\title{
KAJIAN TATA NIAGA KAYU RAKYAT DI PULAU JAWA BAGIAN BARAT
}

\author{
The Study of Marketing Channel of the community timber \\ in the western part of Java Island
}

\section{Rachman Effendi}

\author{
PusatPenelitian dan Pengembangan Perubahan Iklim dan Kebijakan Pusat \\ Jalan Gunung Batu No. 5 Kotak Pos 165 Bogor 16610 \\ Telepon (0251) 8633234, 7520067; Fax. (0251) 8638111
}

Naskah masuk : 9 November 2010; Naskah diterima : 3 September 2011.

\begin{abstract}
The demand of Timber in Western Java, especially in West Java, DKI. Jakarta and Banten, is currently derived from community forests (HR), timber industrial estates (HTI) and the Natural Forest (HA). When the supply of logs from natural forests has decreased while the production of timber industrial estates is not reliable, then the community forest is expected to play an important role as a supplier of wood both for domestic and export industry. Circulation of the community timber in the western part of Java island, still not yet known so that we made the study of the circulation timber trade system. The purpose of this study is to determine the distribution chain trade system and the marketing margin of the community timber in the western part of Java island namely West Java, DKI Jakarta and Banten. The research was conducted for one year starting from July until November 2009 in West Java, DKI. Jakarta and Banten. Based on these findings, chain timber trade system of the people in West Java, DKI Jakarta and Banten consists of 6 (six) channels which are: 1) Farmer-end consumers, 2) Farmer-broker-end consumers, 3) farmer-brokerwood industry 4) The farmer-industry-sawing timber merchant wood-processing industry of wood-end customers, 5) Farmer-trader-broker-processing industry of wood-end consumers. Kind of timber traded is acacia wood, African, mahogany, teak, sengon, Gmelina and durian wood. While based on the calculations of marketing margins, from the fifth market channels that have the greatest profit margin is a first channel, first channel is the shortest line and farmers selling direct to the end consumer of a timber without going through intermediaries.
\end{abstract}

Keywords: Distribution, margin of market channel, wood community

\begin{abstract}
ABSTRAK
Kebutuhan kayu di Pulau Jawa bagian barat khususnya Jawa Barat, DKI. Jakarta dan Banten, saat ini diperoleh dari hutan rakyat (HR), Hutan Tanaman Industri (HTI) dan Hutan Alam (HA). Ketika pasokan kayu bulat yang berasal dari hutan alam produksi mengalami penurunan sementara pasokan kayu dari HTI belum dapat diandalkan, maka hutan rakyat diharapkan dapat berperan penting sebagai pemasok kayu baik untuk kebutuhan industri dalam negeri maupun ekspor. Peredaran kayu rakyat di pulau Jawa bagian barat, masih belum dapat diketahui sehingga dilakukan kajian mengenai tata niaga peredaran kayu. Tujuan dari penelitian ini adalah untuk mengkaji rantai tata niaga dan distribusi pemasaran kayu rakyat di bagian barat Pulau Jawa yaitu Jawa Barat, DKI Jakarta dan Banten. Penelitian ini dilaksanakan selama satu tahun mulai bulan Juli sampai dengan November 2009 di Jawa Barat, DKI Jakarta dan Banten. Berdasarkan hasil penelitian tersebut, rantai tata niaga kayu rakyat di Jawa Barat, DKI Jakarta dan Banten terdiri dari 6 (enam) saluran yaitu: 1) Petani-konsumen akhir; 2) Petani-pedagang perantara-konsumen akhir, 3) Petani-pedagang perantara-industri pengolahan kayu 4) Petani-industri penggergajian-pedagang kayu-industri pengolahan kayu-konsumen akhir, 5) Petani-pedagang perantara-pedagang kayu-industri pengolahan kayu-konsumen akhir. Kayu yang diperdagangkan adalah kayu akasia, afrika, mahoni, jati, sengon, gmelina dan kayu durian, sedangkan berdasarkan hasil perhitungan marjin pemasaran, dari ke
\end{abstract}


lima saluran tersebut saluran yang memiliki distribusi margin keuntungan paling besar adalah saluran satu. Kondisi tersebut terjadi karena saluran satu merupakan saluran terpendek dan petani langsung menjual kayu ke konsumen akhir tanpa melalui perantara.

\section{Kata kunci : Distribusi, kayu rakyat, marjin tata niaga}

\section{PENDAHULUAN}

\section{A. Latar Belakang}

Kebutuhan kayu di Pulau Jawa Bagian Barat khususnya Jawa Barat, DKI Jakarta dan Banten, saat ini diperoleh dari hutan rakyat (HR), Hutan Tanaman Industri (HTI) dan Hutan Alam (HA). Ketika pasokan kayu bulat yang berasal dari hutan alam produksi mengalami penurunan sementara pasokan kayu dari HTI belum dapat diandalkan, maka hutan rakyat diharapkan dapat berperan penting sebagai pemasok kayu baik untuk kebutuhan industri dalam negeri maupun ekspor.

Hutan rakyat sebagai salah satu alternatif pemasok kayu, memiliki potensi yang cukup besar untuk dikembangkan, guna memenuhi kebutuhan permintaan pasar lokal dan industri. Pengusahaan hutan rakyat, saat ini masih bersifat tradisional, sehingga pengusahaan hutan rakyat, mencakup kegiatan: produksi, industri, pemasaran dan kelembagaan, belum dilaksanakan secara optimal (Hafsari, 2009). Faktor yang penting dalam pengembangan dan pemanfaatan kayu rakyat salah satunya adalah tataniaga kayu rakyat. Dalam tataniaga kayu rakyat saat ini dirasa masih belum berjalan secara optimal, hal ini dikarenakan masih adanya distribusi margin pemasaran yang tidak merata.

Sebagaimana komoditas pertanian pada umumnya, sifat dari hasil produksi kayu rakyat yang berada di Pulau Jawa Bagian Barat adalah: volume atau jumlahnya yang relatif kecil; letaknya yang bertebaran pada kondisi topografi yang sulit; jauh dari konsumen atau industri pengolahan; kualitas kayu yang relatif lebih rendah dibandingkan dengan kualitas yang diharapkan oleh konsumen; dan waktu panen yang tidak menentu. Keadaan-keadaan ini memungkinkan adanya keterlibatan pelaku lain yaitu pedagang pengumpul (tengkulak) dalam pemasaran kayu rakyat yang berperan menghubungkan petani dengan konsumen kayu rakyat, sehingga jumlah pelaku pemasaran kayu menjadi lebih banyak dan mengakibatkan harga yang diterima petani menjadi lebih rendah.

Terkait dengan hal tersebut diatas, peredaran kayu rakyat di Pulau Jawa bagian Barat saat ini, masih belum dapat diketahui sehingga dilakukan kajian mengenai tata niaga peredaran kayu rakyat. Informasi tersebut diharapkan berguna sebagai bahan masukan dalam penyusunan kebijakan untuk memacu efektifitas dan efisiensi peredaran kayu untuk bahan baku industri pengolahan kayu dalam rangka perbaikan tataniaga kayu dan pembuatan keputusan untuk pengembangan pengelolaan hutan khususnya hutan rakyat di Jawa Bagian Barat.

\section{B. Tujuan Penelitian}

Tujuan dari penelitian ini adalah untuk mengkaji rantai tata niaga dan distribusi margin pemasaran dari kayu rakyat di bagian barat pulau jawa yaitu Jawa Barat, DKI Jakarta dan Banten.

\section{METODE PENELITIAN}

\section{A. Kerangka Analisis}

Alur pemikiran kajian tata niaga kayu rakyat terlihat sebagaimana Gambar 1. Pada gambar tersebut jalur distribusi pemasaran kayu rakyat dimulai dari para petani pengelola hutan rakyat sebagai sumber produksi kayu dijual melalui lembaga-lembaga perantara (tingkat desa, kecamatan, kabupaten dst) kemudian langsung ke industri (primer, sekunder, downstream) sebagai konsumen ataupun ke pedagang besar bahan bangunan (termasuk kayu). Jalur tata niaga selanjutnya setelah dari pedagang besar kemudian ke pedagang pengecer. Adapula sebagian kayu hasil industri yang ada di pedagang besar langsung dijual ke industri perumahan dan atau ke pedagang pengecer. 


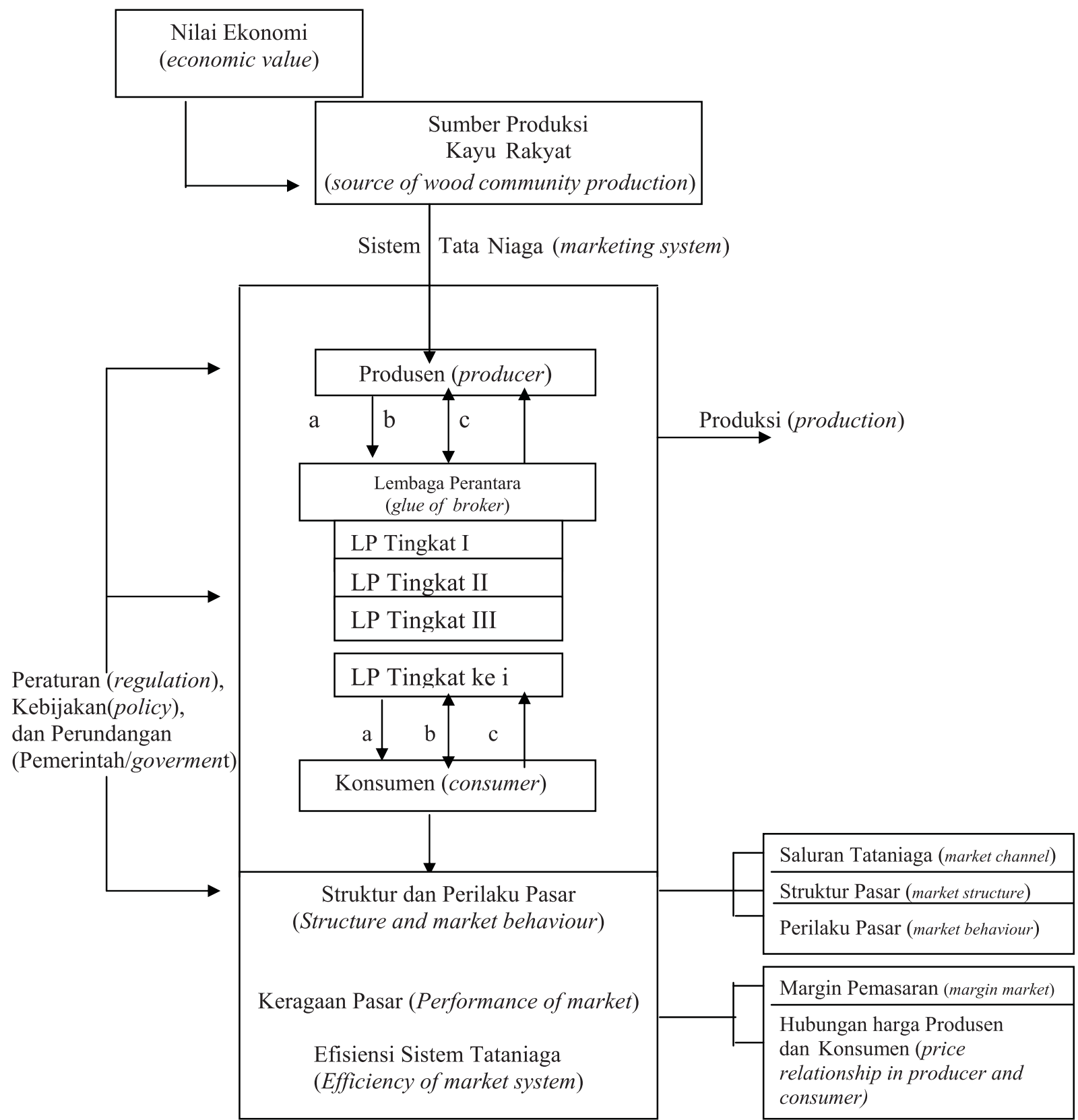

Keterangan (Remarks) :

$\mathrm{a}=$ arus produk (satu arah)/ product flow (one way)

$\mathrm{b}=$ informasi (information)

$\mathrm{c}=$ arus uang (satu arah)/ flow of money (one way)

Gambar(Figure) 1. Alur pikir rantai tata niaga kayu rakyat (The chronology of market channel of wood community)

\section{B. Metode Pengambilan Contoh}

Obyek penelitian atau unit contoh pada kajian ini adalah petani, padagang kecil, pedagang besar (industri) yang bergerak di bidang pengelolaan kayu rakyat (pelaku usaha kayu), dan lembaga lain yang terlibat dalam tata niaga kayu. Responden pada objek penelitian tersebut difokuskan pada daerah penghasil kayu rakyat antara lain Jawa Barat (Ciamis, Sukabumi, Purwakarta), Banten (Pandeglang, Serang dan Lebak) dan DKI Jakarta sebagai konsumen kayu rakyat. Pemilihan dan pengambilan contoh dilakukakan secara purposive pada lokasi yang dianggap dapat mewakili satu kabupaten terpilih. 


\section{Pengumpulan Data}

Data lapangan dikumpulkan berdasarkan hasil penelitian tahun 2007 dan pada bulan Juli sampai dengan November 2009 dengan metode survei melalui pengamatan langsung di lapangan. Data primer diperoleh melalui wawancara dan pengamatan langsung ke lapangan. Responden dalam kajian ini produsen kayu rakyat yaitu petani hutan rakyat, tingkat pedagang kayu, dan industri pengolahan kayu.

\section{Analisis Data}

Data lapangan dianalisis secara deskriptif untuk melihat hasil pemantauan saluran tata niaga kayu rakyat. Sistem tata niaga kayu rakyat (KR) ditentukan berdasarkan margin tata niaganya dan dihitung dengan persamaan sebagai berikut:

$$
\begin{aligned}
& \mathrm{M}_{\mathrm{i}}=\mathrm{Pr}_{\mathrm{i}}-\mathrm{Pf}_{\mathrm{i}} \\
& \mathrm{M}_{\mathrm{i}}=\mathrm{C}_{\mathrm{i}}+\pi_{\mathrm{i}}
\end{aligned}
$$

dimana

$\mathrm{M}_{\mathrm{i}}=$ marjin tata niaga $\mathrm{KR}$ pada lembaga tata niaga ke-i $\left(\mathrm{Rp} / \mathrm{m}^{3}\right)$

$\mathrm{Pr}_{\mathrm{i}}=$ harga jual KR pada lembaga tata niaga ke-i $\left(\mathrm{Rp} / \mathrm{m}^{3}\right)$

$\mathrm{Pf}_{\mathrm{i}}=$ harga beli KR pada lembaga tataniaga ke-i $\left(\mathrm{Rp} / \mathrm{m}^{3}\right)$

$\mathrm{C}_{\mathrm{i}}=$ biaya tataniaga $\mathrm{KR}$ pada lembaga tataniaga ke-i $\left(\mathrm{Rp} / \mathrm{m}^{3}\right)$

$\pi_{\mathrm{i}}=$ margin keuntungan $\mathrm{KR}$ pada lembaga tataniaga ke-i $\left(\mathrm{Rp} / \mathrm{m}^{3}\right)$

\section{HASIL DAN PEMBAHASAN}

\section{A. Hasil}

\section{a. Karakteristik Hutan Rakyat}

Hutan rakyat merupakan hutan yang tumbuh dilahan milik rakyat. Pulau Jawa Bagian Barat merupakan daerah yang memiliki potensi hutan rakyat yang cukup besar, sebagai contoh Jawa Barat dan Banten. Hutan rakyat di Jawa Barat banyak tersebar di wilayah Ciamis, Sukabumi, Purwakarta, Cianjur, Garut, Tasikmalaya dan Bandung.

Penelitian ini dibatasai hanya pada tiga tempat yaitu: Ciamis, Sukabumi dan Purwakarta. Sedangkan untuk wilayah Banten lokasi penelitian dilakukan di Pandeglang, Serang dan Lebak. Luasan dan potensi yang dihasilkan dari lokasi penelitian tersebut tertera pada Tabel 1.

Adapun komoditi kayu yang ditanam di lokasi tersebut (Tabel 1) adalah sengon (Falcataria moluccana), manii (Meosopsis eminii), mahoni (Swietenia macrophylla) dan jati (Tectona grandis). Hasil produksi dari komoditi tersebut sebagian besar di pasarkan keluar wilayah dan salah satunya DKI Jakarta.

\section{a. Tata Niaga Kayu Rakyat}

\section{1) Saluran Tata niaga}

Saluran tata niaga kayu rakyat menggambarkan proses pendistribusian kayu dari petani di lahan milik sebagai produsen kayu sampai ke konsumen. Konsumen pada saluran tataniaga kayu dari petani adalah masyarakat rumah tangga, pedagang dan industri (pengolah kayu). Lembaga-lembaga tata niaga yang terlibat dalam pemasaran kayu rakyat di daerah penelitian adalah petani, pedagang pengumpul, industri penggergajian dan pedagang kayu (sawmill), pedagang kayu (eceran), dan pembuat perabotan kayu. Skema saluran tata niaga kayu dari tingkat petani hingga konsumen tertera pada Gambar 2.

Berdasarkan Gambar 2, rantai tata niaga kayu rakyat yang ada memiliki 6 saluran tata niaga, dan keenam saluran tersebut melibatkan beberapa aktor yang berbeda dan komposisi model saluran pemasaran yang terjadi didasarkan kepada jenis kayu yang dihasilkan.

Tabel(Table) 1. Luas dan potensi kayu rakyat di lokasi penelitian (The land area and potential timber of

\begin{tabular}{|c|c|c|c|c|c|c|}
\hline \multirow{2}{*}{ No } & \multirow{2}{*}{ Lokasi (Location) } & \multirow{2}{*}{$\begin{array}{c}\text { Luasan (land } \\
\text { area) } \\
\text { (ha/hectare) }\end{array}$} & \multicolumn{4}{|c|}{ Potensi jenis $\left(\mathrm{m}^{3} /\right.$ tahun $)$ (Potential type of tree $\left(\mathrm{m}^{3} /\right.$ year $\left.)\right)$} \\
\hline & & & Sengon & Manii & Mahoni & Jati \\
\hline 1 & Ciamis & $28.832,44$ & $113.956,00$ & - & $76.959,00$ & $22.702,27$ \\
\hline 2 & Sukabumi & $30.162,86$ & $20.819,47$ & $13.896,70$ & $4.623,10$ & $6.952,70$ \\
\hline 3 & Purwakarta & $9.119,00$ & $1.456,00$ & 263,80 & $1.422,00$ & $2.110,00$ \\
\hline 4 & Banten & $11.728,43$ & $227.720,00$ & $31.142,00$ & $15.742,40$ & $24.156,47$ \\
\hline
\end{tabular}
community forest)

Keterangan (Remarks): Data hasil olahan (The Data is processing result) 
Untuk jenis kayu rakyat berupa sengon dan manii memiliki 5 (lima) komposisi saluran sedangkan untuk jenis jati dan mahoni memiliki komposisi 3 (tiga) saluran. Rantai tata niaga kayu sengon dan beberapa jenis kayu lainnya dari tingkat produsen (petani) dapat digambarkan sebagai berikut :

1) Petani-Konsumen akhir (Saluran 1)

2) Petani-Pedagang Perantara-Konsumen Akhir (Saluran 2)
3) Petani-Pedagang Perantara-Industri Pengolah Kayu (Saluran 3)

4) Petani-Sawmill-Pedagang kayu-Industri Pengolah Kayu dan Konsumen Akhir (Saluran 4)

5) Petani-Pedagang Perantara-Pedagang kayuIndustri Pengolah kayu dan Konsumen Akhir (Saluran 5)

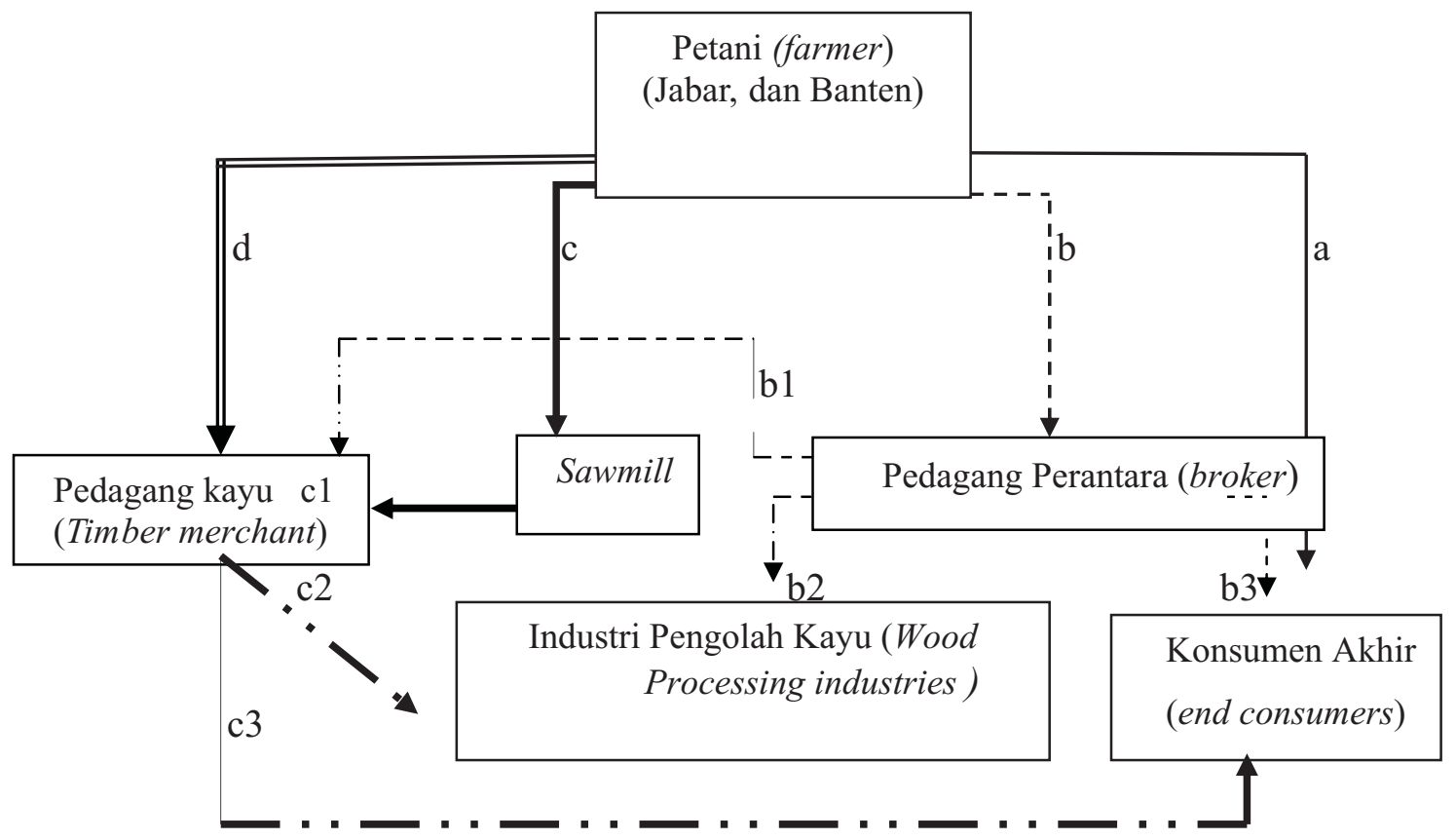

Gambar(Figure) 2. Saluran Tata niaga kayu rakyat di Pulau Jawa Bagian Barat (The market channel of timber community in West Java Island)

Keterangan (Remarks):

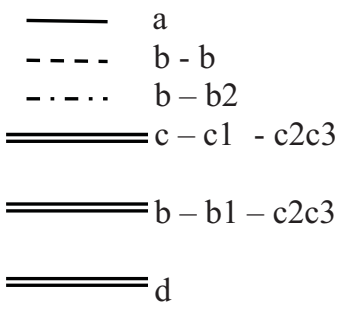

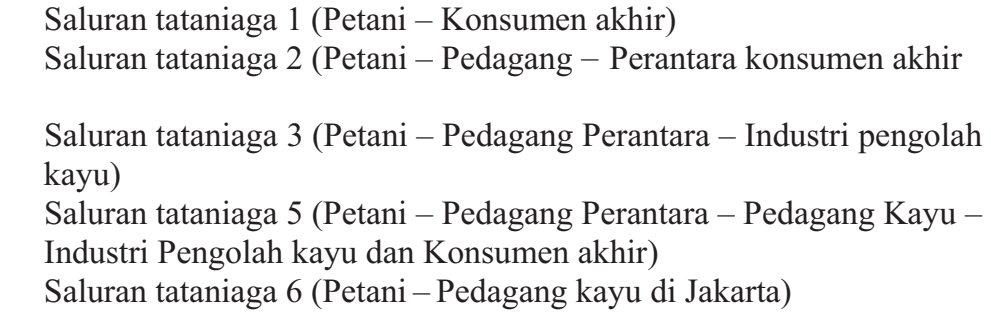

\section{b. Margin Pemasaran}

Pengukuran efisiensi tataniaga yang dilakukan dengan konsep marjin pemasaran (MP) dapat dilihat dari beberapa sudut pandang. Margin pemasaran dari setiap lembaga tataniaga yang terlibat dari masing-masing saluran tata niaga disajikan pada Tabel Lampiran 1.

Pada sisi petani, pemasaran dikatakan efisien bila dapat memberikan tingkat harga yang relatif tinggi. Atas dasar sudut pandang ini, seperti yang terlihat pada Lampiran 1. Sistem pemasaran kayu sengon dan jenis-jenis lainnya di saluran 1 lebih efisien daripada saluran 2, 3, 4, dan 5, sebab petani menjual kayu sudah dalam bentuk kayu gergajian yang harga jualnya di pasar lebih tinggi daripada bentuk kayu bulat dan pohon berdiri. Pada saluran 1 petani menerima harga per meter kubik kayu senilai Rp 325.000,- (kayu gergajian), sehingga diperoleh keuntungan bersih petani sebesar Rp 177.000 ,- per meter kubik (setelah dikurangi biaya pengolahan dan pemasaran sebesar Rp 148.000 ,- per meter kubik) 


\section{B. Pembahasan}

Model atau pola tata niaga jenis-jenis kayu rakyat merupakan pola atau cara yang dilakukan produsen atau petani dalam memasarkan produkproduk kayu rakyat. Tolak ukur atau aspek yang menjadi penyusunan pola atau model tata niaga kayu rakyat tersebut antara lain: (1) kelompok jenis kayu yaitu jenis-jenis kayu yang dikelompokkan ke dalam jenis kayu yang memiliki nilai ekonomi tinggi, menengah atau sedang, dan rendah, (2) jenis atau bentuk produk yaitu bentukbentuk pemanfaatan produk, (3) saluran pemasaran produk (Effendi dan Antaatmaja, 1999).

Pada kelompok jenis kayu tertentu yang memiliki nilai ekonomi menengah dan tinggi pada pasar kayu lokal seperti jati dan mahoni memiliki rantai tata niaga yang khusus, berdasarkan jenis produk akhir yang dipasarkan walaupun dapat berada pada saluran tataniaga kelompok jenis kayu sengon. Rantai tata niaga jenis jati dan mahoni dari tingkat produsen (petani) adalah sebagai berikut : (1) Petani-Pedagang PerantaraIndustri Pengolah Kayu dan Konsumen Akhir (Saluran 2 dan 3); (2) Petani-Pedagang Perantara-Pedagang Kayu (Saluran 6) dan (3) Petani-Pedagang kayu (di luar provinsi seperti di Jakarta (Saluran 6).

Keberhasilan petani untuk meningkatkan pendapatannya melalui saluran tata niaga kayu rakyat tergantung pada kemampuan petani secara individual dalam memanfaatkan peluang pasar yang dapat memberikan tingkat keuntungan relatif lebih tinggi (Darusman dan Nurheni, 2007). Ditinjau dari sudut pandang lembaga pemasaran, sistem pemasaran dikatakan efisien bila dapat memberikan keuntungan relatif tinggi dan biaya pemasaran relatif rendah. Hal tersebut dapat dilihat dari rasio antara keuntungan dan biaya pemasaran, bila rasio keuntungan dan biaya pemasaran lebih besar dari satu, atau minimal keuntungan dan biaya pemasaran adalah sama. Rasio keuntungan dan biaya setiap meter kubik kayu gergajian yang diterima petani pada saluran 1 adalah 1.20 artinya setiap $\mathrm{Rp} 100$,- biaya produksi yg dikeluarkan, petani memperoleh pendapatan sebesar Rp 120,- atau keuntungan sebesar Rp 20,- (20\%). Saluran 1 ini dapat dikatakan efisien, namun hanya $2,94 \%$ responden yang melakukannya dikarenakan keterbatasan konsumen akhir yang ada.

Sistem tataniaga kayu rakyat cenderung merugikan petani, terlalu menguntungkan pengusaha dikarenakan : (1) penjualan dalam bentuk tegakan (borongan) sehingga keuntungan rendah, demikian juga tengkulak pembeliannya dengan sistem ijon; (2) penjualan dalam bentuk kayu bulat ke luar daerah, nilai tambah bagi masyarakat rendah (Darusman dan Nurheni, 2007).

Secara rinci beberapa permasalahan tata niaga kayu rakyat dapat dikelompokan kedalam lembaga yang terlibat pada saluran tata niaganya antara lain :

1) Petani sebagai produsen kayu rakyat : a) organisasi petani lemah, b) kemampuan ekonomi rendah, c) profit marjin rendah (kecil), d) pengetahuan/ keterampilan rendah, dan e) sharing terhadap kerusakan lingkungan besar (erosi, tata air, oksigen, iklim mikro, mengurangi defisit bahan baku nasional).

2) Industri kayu rakyat (sawmill) : a) kemampuan teknologi rendah, b) menghasilkan banyak limbah (belum dimanfaatkan secara efisien), pemborosan sumber daya alam, c) sharing terhadap pemeliharaan kualitas lingkungan rendah, d) marjin profit besar (tidak proporsional), e) komitmen pengusaha terhadap peningkatan kesejahteraan petani rendah.

3) Pedagang perantara/Tengkulak : a) pedagang membeli dalam bentuk tegakan dengan harga yang rendah, b) marjin profit cukup besar, c) sharing terhadap lingkungan rendah, d) informasi pasar ke produsen kurang lancar.

4) Pengusaha/eksportir kayu olahan : a) pasokan tidak kontinyu, b) menghendaki kualitas kayu yang tinggi, c) harga terlalu rendah, d) perhatian terhadap lingkungan kurang.

5) Pemerintah Daerah (sebagai faktor produksi): (1) kemampuan terbatas (SDM, fasilitas), (2) peraturan perundangan lemah, c) organisasi belum efektif.

\section{KESIMPULAN DAN SARAN}

\section{A. Kesimpulan}

1. Pola saluran tata niaga kayu rakyat memiliki enam saluran mulai dari petani hingga konsumen. Saluran tata niaga untuk jenis kayu sengon dan durian secara dominan ditemukan pada pemasaran kayu di Pulau Jawa Bagian Barat dapat menggambarkan saluran pemasaran dan model pemasaran beberapa jenis kayu lainnya. Pola saluran tata niaga kayu sengon dan beberapa jenis kayu lainnya dari tingkat produsen (petani) adalah sebagai berikut: 
1) Petani-Konsumen akhir (Saluran 1)

2) Petani-Pedagang Perantara-Konsumen Akhir (Saluran 2)

3) Petani-Pedagang Perantara-Industri Pengolah Kayu (Saluran 3)

4) Petani- Sawmill - Pedagang kayu-Industri Pengolah Kayu dan Konsumen Akhir (Saluran 4)

5) Petani-Pedagang Perantara-Pedagang kayu-Industri Pengolah kayu dan Konsumen Akhir (Saluran 5).

Saluran pemasaran untuk jenis kayu jati dari petani adalah sebagai berikut :

1) Petani-Pedagang Perantara-Industri Pengolah Kayu dan Konsumen Akhir (Saluran 2 dan 3)

2) Petani-Pedagang Perantara-Pedagang Kayu (Saluran 6)

3) Petani-Pedagang kayu (di luar propinsi seperti di Jakarta (Saluran 6)

2. Hasil analisis penyebaran marjin untuk kayu sengon menunjukkan bahwa pola saluran 1 petani konsumen akhir mempunyai sistem pemasaran lebih efisien dibandingkan saluran 2, 3, 4, dan 5 karena tingkat harga yang diterima petani paling tinggi yaitu Rp 325.000,- per m3 kayu gergajian dan keuntungan yang diterima sebesar Rp 177.000,- (54,46\%) serta rasio keuntungan dan biaya pemasaran mencapai 1,20.

\section{B.Saran}

1. Saluran tataniaga sebaiknya dapat diperpendek untuk mengurangi biaya-biaya pengangkutan sehingga kedudukan petani sebagai produsen menjadi lebih kuat.

2. Pemerintah perlu mempertimbangkan untuk membuka pasar kayu bulat yang bersaing karena selama ini di Indonesia tidak pernah ada pasar terbuka untuk kayu bulat, sehingga industri pengolahan kayu dapat mempunyai kesempatan yang sama untuk memperoleh bahan baku.

\section{DAFTAR PUSTAKA}

Darusman, D. dan W. Nurheni. 2007. Aspek Ekonomi Hutan Rakyat (Skim Pendanaan). Makalah pada Stadium General Pekan Hutan Rakyat II tg. 30 Oktober 2007 di Ciamis. Jawa Barat.

Dinas Kehutanan Provinsi Banten. 2006. Statistik Dinas Kehutanan Dinas Kehutanan Propinsi Banten. Serang, 2007.

Dinas Kehutanan Propinsi Jawa Barat. 2007. Laporan Akuntabilitas Kinerja Instansi Pemerintah (LAKIP) Dinas Kehutanan Provinsi Jawa Barat, Bandung, Tahun 2006.

Effendi, R. dan S. Antaatmaja. 1999. Pola Distribusi Kayu Penghara untuk Industri Penggergajian di Daerah Jawa Tengah. Jurnal Penelitian Hasil Hutan, Vol. 6 No. 2 (1989) pp. 94-99. Pusat Penelitian dan Pengembangan Teknologi Hasil Hutan. Bogor.

Hafsari, A. 2009. Keragaan Industri Kayu Rakyat Di Wilayah Cianjur Selatan (Studi Kasus Di Kecamatan Cibinong dan Kecamatan Tanggeung) [Skripsi]. Bogor: Departemen Manajemen Hutan. Fakultas Kehutanan. Institut Pertanian Bogor

Hartono. 2004. Strategi Pemantapan Pangsa Pasar Produk Primer dan Sekunder yang Unggul. Makalah Tanggapan Dalam Seminar Strategi Pengembangan Industri Perkayuan Yang Lestari, yang diselenggarakan oleh Badan Litbang Kehutanan dan ITTO, di Jakarta, 7 Desember 2004. 


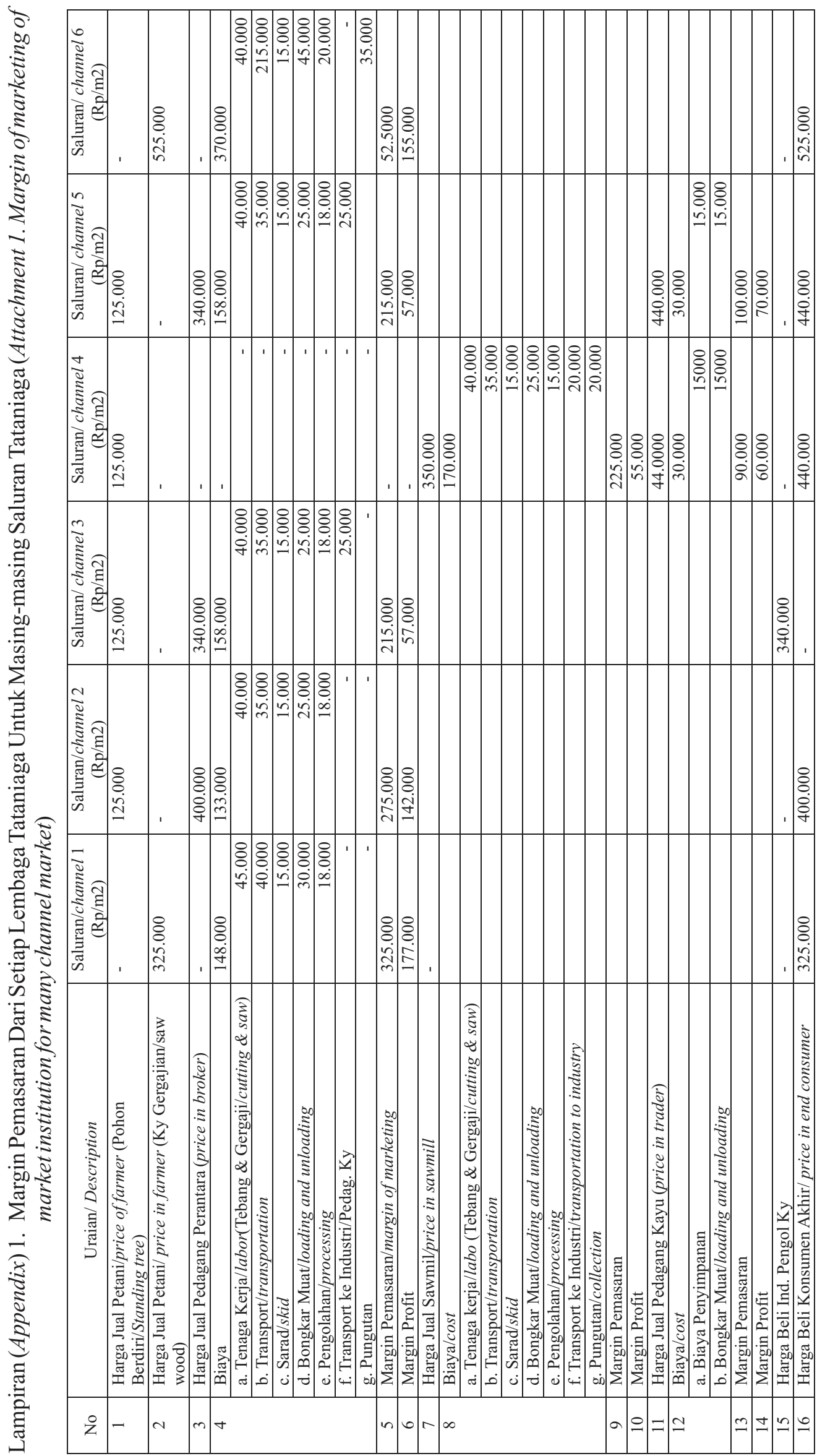

